\title{
NATIVE OBSTETRIC PRACTICE IN CHINA.
}

\author{
By AGNES L. COUSINS, L.R.C.P.S. (Edin.), M.D. (Brux.), Medical \\ Missionary in charge of Margaret Hospital for Women and \\ Children, Hankou, China.
}

Chrsa is so vast a land that customs are bound to differ in different provinces and parts of the Empire. The practices mentioned in this paper are common in the province of Hupeh and more especially are met with in the town of Hankow. The people of Central China are neither so fierce and cruel as the Northerners, nor so treacherous as the Southerners of China are represented to be.

Obstetric practice is mainly in the hands of ignorant and dirty midwives, and nearly every case one meets in practice has been mismanaged by the attendant. Gynæcology is, on the other hand, undertaken by the native medical man, who is, according to European ideas, merely a quack. The Chinese do not require their doctors to qualify or to take a degree, and often they are quite illiterate men.

It is perhaps needless to say that vaginal examinations are never made by the native doctors, and the hopelessness of treatment is further increased by the seclusion of the patient. Diagnosis is often made by the pulse, of which the Chinese aver there are six at each wrist. From the pulse the state of the internal organs can be at least surmised if not accurately diagnosed. Alteration of one pulse will indicate abdominal mischief, of another cerebral, and so on. The doctor often does not see his patient, or only sees a tongue protruded through an aperture in a curtain, or feels a pulse, the arm being pushed through the curtain; if the patient is seen he makes no local examination, and therefore the prescription is written for the relief of symptoms and is often "shotty" and long. Sometimes, however, they quickly succeed in effecting a cure, if not, they try again and again. If, however, the patient grows worse and death seems imminent, the native practitioner immediately pronounces the case incurable, or may in a few places send them to a European doctor; in any case he rids himself of all responsibility.

Taken generally, at least as far as my observation goes, the native women have roomy pelves, labour is quicker than with Europeans, and pain is either less intense or better borne. Yet in practice one meets with many appalling cases because, as a European, one is rarely called to a simple and normal case.

The midwives are usually of a very low class, so much so that the 
sons and descendants of a woman employed in this work are not permitted to take a degree, and are therefore debarred from taking office for three generations. A practice is often handed down from mother to daughter and so on. One positively filthy young woman assured me her ancestors had been engaged in the trade for 100 years; and as one surveyed her filthy clothes, her dirt-begrimed face and hands, her long and muddy nails, one secretly wondered how many souls had been helped into enternity through the ministrations of this one family.

One would not expect antiseptic or aseptic treatment among the Chinese, but quite apart from these, even ordinary cleanliness is unthought of. No Chinese midwife $I$ have met has ever seemed to think it necessary to wash her hands, or to cleanse the external genitals of the patient before making a vaginal examination. After delivery they may or may not run their finger tips through a little water. Consequently the germs of disease are carried from case to case and puerperal fever is common. One case comes to my memory. A primipara, aged 18, had been in labour four days. A very "septic" midwife was in attendance. The patient, who looked exceedingly ill, was propped up in bed eating thick pork broth with rice and capsicums as a flavouring. The pains had stopped; the patient's temperature was $105^{\circ} \mathrm{F}$; the pulse between 130 and 140 and the breathing rapid. On examination the vulva and external parts were very odematous, swollen and congested. The presentation was an occipito-posterior one; the head was jammed in the pelvis, and the bladder was much distended. There was a tear of the posterior vaginal wall. The midwife had adopted an expectant treatment combined with generous diet, and this in spite of the fact that matters grew steadily worse. Catheterisation, incisions in the œdematous tissues, and forceps brought the case to an end. The posterior vaginal wall tore like so much paper. The child was dead, and in spite of subsequent treatment carried out by our trained European nurse, the woman died some 48 hours later.

A year afterwards this midwife came to me and begged me to give her some lotion to use for her hands as she had herself noticed that infection was being carried from woman to woman, and that many of her patients were dying from the effects.

The months of pregnancy are usually reckoned as ten by the Chinese. The women take no special care during these months and abortion and miscarriage are very common. They do not retire to bed at such times, consequently the hæmorrhage is sometimes alarming. If the patient grows faint with it the friends will put her to 
bed but prop her up, so that the poor, fainting creature is made to sit as nearly upright as possible to prevent the discharge gravitating upwards to the heart. Treatment is to give some native hæmostatic, purgatives, or apply counter irritation to the abdomen.

The women's quarters in Chinese houses are usually small and dark, often without a window, and with room only for the bed and a narrow path on one side of it. Obstetric work carried on under these conditions is not always encouraging. When labour commences, the midwife is sent for and makes a vaginal examination, and seems able generally to tell whether the head or breech presents. If the head presents, the position is not taken into account, things are said to be going on well. If the first stage is slow the midwife endeavours to rupture the bag of membranes, while the patient is exhorted to bear down. After this early treatment a slow, lingering labour may result, but the woman has received a little encouragement, and believes that matters are expedited.

The Chinese never deliver in the left lateral position, and rarely in the dorsal. As labour advances the patient is usually propped up in a squatting position with the buttocks resting just at the edge of a bed or chair (which are always low); her thighs are supported on the knees of two women sitting on either side, and often her arms rest on their shoulders. A third woman from the rear puts her arms round the patient's abdomen, and with the pains makes pressure downwards and backwards in an effort to express the child.

Meanwhile on the floor between the patient's knees, which are widely separated, is a stool and on it a receiving bath, in front of which the midwife kneels. She endeavours to stretch the vagina by inserting her fingers and pulling the vaginal walls apart, much in the way one dilates the sphincter ani with the thumbs before operating for hæmorrhoids.

A tear of the perineum is not considered of any consequence either by the patient or the midwife. If there is delay at the outlet native drugs are given to cause relaxation of perineal structures. Sometimes, however, they apply counter irritation to the vestibule and clitoris instead of giving drugs. This is done either by selecting a sharp fragment of a broken basin, and using it to scarify the part, or by inserting red-hot needles. I have seen a swelling as large as a walnut resulting and complicating delivery.

If there is no regular attendant the patient will often deliver herself, assuming a squatting or kneeling position, with a flat wooden footbath under her, and supporting her arms on a chair, a bed or some other article or furniture. 
In Central China post-partum hæmorrhage is rare, at least in my experience. This may perhaps to some extent be accounted for by the regetarian diet of the Chinese. They rarely eat meat, though fish and fowl are sometimes and more commonly eaten.

Another thing one notices is how few women suffer from varicosity of the veins. Owing to the practice of binding the feet the lower extremities are poorly developed and ill nourished, and probably the blood supply to the parts is small.

There are among the midwives and native practitioners those who venture to do a crude embryotomy. Women come to us to repair the mischief done by them.

CASE i. Primipara had a history of very prolonged labour, " native doctor(!) had cut up the baby and taken it away in bits." The mother was ill for months with fever, abdominal and vaginal pain, and had not menstruated since (some two years later). On examination there was no vaginal opening at all, the whole had securely cicatrised.

CASE ii. Woman aged 40, multipara. Transverse presentation. In labour four or five days. Patient says the arm of the baby was lying outside the vulva. Native doctor took away the foetus in pieces. Patient had rigors, fever, and great abdominal pain, especially on the left side. Her friends carried her 60 miles on a cane couch to our hospital.

On examination her temperature was $104 \cdot 6^{\circ} \mathrm{F}$.; pulse 125 ; patient much collapsed after the journey; the effluvium was horrible. Per vaginam the uterus was still large, the os easily admitted two fingers, the left tube was enlarged and swollen, hot and tender. The lochia were very fœtid and contained pus. There was also a large swelling in the left iliac region which proved to be an abscess. On opening this the following morning, after evacuating the pus, I was surprised to find three or four large round worms (Ascaris lumbricoides), in the wound. As to the native treatment of breech cases I have only seen one which had been treated or ill-treated by a midwife. When I arrived the woman was lying propped up on the edge of the bed, with her legs widely stretched apart on two chairs, and the baby, caught by its head within the uterus, hanging helplessly down between. The presentation was sacro-anterior, and the occiput had stuck behind the pubes. To meet the difficulty the midwife " to make room for the head," as she said, had cut the recto-vaginal septum and perinæum. The poor, bleeding, suffering woman seemed nearly at her last gasp, and was naturally fearful of further treatment, especially at the hands of a foreigner. After tying a few arteries, and to 
some extent stopping the hæmorrhage consequent on the midwife's operation, I delivered in the usual way and the placenta followed immediately. The section of vagina had been made with a pair of large scissors. In spite of my entreaties that the patient might be brought to hospital for proper nursing and for repair of the vagina and perineum, the woman was left to her fate and died the next evening. Native superstition makes it a terrible thing for a woman to die undelivered; but if the child is born and she dies subsequently, the family accept it as fate, and with the calm indifference and philosophy of the Oriental mind go through the ceremonies of burial and mourning with dignity, and in a few months the mourning husband assumes again the character of a happy bridegroom with the same dignified ease and facility.

Miss Gough, L.S.A., told me of a breech case to which she was called. On arrival she found a rope tied round the fotal legs and two strong men applying traction from the outer side of the bedroom door. The two men tugged with might and main, but the fœtal head still remained in utero.

Rupture of the uterus is by no means uncommon, neither is it always fatal. A friend attended a case where the uterus was ruptured, on removing the placenta manually she found it had partly escaped into the abdominal cavity. The patient, however, made a good recovery.

A foreign or European doctor is rarely called to a normal case, except among personal friends. If nature can with little or no aid produce the child alive the midwife takes the credit, if nature is at fault the case is usually mismanaged and things made a hundred times worse. There are then two courses open, the first and most common is to invoke the aid of the gods by calling in the priests and diviners, and the second is to call in a foreign doctor if one is anywhere near. Sometimes the two are combined. This once happened in my experience; the men of the family sent for me, while the women sent for the priests. The case was quite normal but slow. This was natural enough too, as the wife, who was one of several, was a young and beautiful primipara of sixteen. The patient was in a cubical opening into a sitting-room, and in this latter room sat four men: two priests incantating from the Buddhistic classics, and divining the fate of the girl; another man sat in a state of partial trance with a shuttle in his hand, which he would throw at intervals, if it fell on its side the fourth man picked it up with a cry of "Suin, suin," or all's well. If, on the contrary it fell on its end the cry came: "There is slight difficulty;" but it fell almost always on its 
side, being very cleverly thrown by the medium. The gentleman in the trance was quite wide awake enough to scrutinise me thoroughly and to cast admiring glances at the Chinese nurse who accompanied me. The priests also murmured incantations over "holy water," though it smelt strangely enough of native spirit. This decoction was given to the patient to drink every fifteen minutes or so. Assuring myself that everything was normal, that neither mother nor child seemed exhausted or in any special danger, and that even if left unaided nature would probably finish her work in an hour or two, I made objections to being mixed up with these heathen practices, and asked that the priests might at least be moved to another room; but they were all too terrified of the power of these diviners to even suggest such a thing, so we retired for an hour or two until they had finished their ministrations.

As a rule as soon as labour is over the patient lies down in bed, but with the head and shoulders bolstered up very high-this is with the idea of quickly draining away the lochia. Under the woman are put layers of Chinese paper, which is very absorbent, and under it again is put a piece of matting. If the floor is wet and soiled it is thickly strewn with sand and ashes; and the whole room seems about as nasty and uncomfortable as it can well be. The patient is at once given a drink of syrup, often with hard-boiled eggs floating in it-a dreadful decoction of which all friends and visitors are expected to partake. The child is not washed, but the cord is dusted with a red powder, which looks a little like calamine, and is then tied up in a piece of paper. Excepting its face and hands a child is often not washed for a year or two.

The women are often up on the day following delivery. Several times calling on the second day I have found the patient looking cheerful and well and moving about as usual-even after forceps have been used or version performed. All the careful instructions given are quite disregarded. Some of the women seem to have no nervous system and to be almost insensitive; others again are the very reverse and take a long time to recover. From all one sees and hears the mortality among women must be very large; but the infant mortality is truly awful, and yet, in spite of this, the Chinese nation is the largest on this earth. 